\title{
Disrupted mothering in Iranian mothers with breast cancer: a hybrid concept analysis
}

\author{
Effat Mazaheri ${ }^{1}$, Akram Ghahramanian ${ }^{2 *} \mathbb{0}$, Leila Valizadeh ${ }^{3}$, Vahid Zamanzadeh ${ }^{4}$ and Tonia C. Onyeka ${ }^{5}$
}

\begin{abstract}
Background: Defining the disrupted mothering would contribute to developing strategies to support mothers with breast cancer. The aim of this study was to analyze the concept of mothering disruption using a hybrid model.

Methods: The Hybrid method for concept analysis was implemented consisting of three phases: theoretical, fieldwork, and final analysis. In the theoretical phase, the literature was searched using electronic databases including PubMed, ScienceDirect, Scopus, ProQuest, Google Scholar, CINAHL, Wiley, Ovid, Magiran, and SID from 2000 to 2020. Any quantitative or qualitative studies published in English or Persian, which were focused on mothering disruption in mothers with breast cancer were included in the study. In the phase of fieldwork, 20 mothers were interviewed to explore the aspects of mothering disruption. The interviews were transcribed and analyzed with conventional content analysis. In the final phase, an overall analysis of the two previous phases was performed.

Results: In the theoretical phase, the following attributes were determined: "disturbance in maternal identity and roles", "maternal insensitivity and unresponsiveness: disconnection physically and psychologically", "the career disruption process" and "biographical disruption". The fieldwork phase explored three themes including "the unbalance between multiple roles","role failure", and "reduced maternal sensitivity". The final synthesis yielded that the main integrated elements of mothering disruption are "disease as threating maternal role and identity", "inability to interpret and respond to child behaviors and needs", and "support for transitioning from being patient toward maternal competency".
\end{abstract}

Conclusion: With a deeper understanding of the term 'disrupted mothering' or 'mothering disruption', healthcare providers will have a foundation to improve cancer care, deliver effective communication and help such mothers cross this disruption and achieve restoration of their mothering role. Future research is needed to validate this concept and explore connections with health outcomes.

Keywords: Breast cancer, Cancer nursing, Disrupted mothering, Hybrid concept analysis, Iran, Maternal role

\section{Background}

'Mothering' is as a woman's emotional and/or physical care for a dependent child [1]. Identity of woman as a mother may be threatened morally and existentially when

\footnotetext{
*Correspondence: ghahramaniana@gmail.com

2 Department of Medical Surgical Nursing, School of Nursing

and Midwifery, Hematology and Oncology Research Center,

Tabriz University of Medical Sciences, Shariati Jonubi Avenue, PO

Box 5138947977, Tabriz, Iran

Full list of author information is available at the end of the article
}

her ability to care for her children is disrupted due to chronic illness [2]. Mothers with cancer are distressed by the periods, when their illness, through hospitalization, fatigue or disability, prevents them for caring for their children as they normally would [3].

Disrupted mothering based on disease and its nature is experienced in different ways, from decreasing physical energy for caring for children, to physical separation and increasing disability, future hospitalization or impending death. Mothering could be disrupted even when women are physically present with their children [4]. 
Women with breast cancer (BC) have expressed feelings such as guilt [3], being different from other mothers [4], shame about their disease and mothering capability, lack of acknowledgement from healthcare professionals regarding their role as mother and a desire to stay alive/healthy so that they can retain their position as primary caregiver [1]. Mousavi et al. emphasize that in Iran, mothers with breast cancer are weaker than healthy mothers in terms of family functioning such as problemsolving, communication, and roles [5]. They have great difficulty in fulfilling their responsibilities regarding child welfare and the stability of family life [6]. Moreover, because of Iran's socioeconomic status and the important role of women as mothers and primary caregivers to children $\mathrm{BC}$ significantly disrupts the mother's ability to function [7].

The concept of disrupted mothering was identified by Jackson who suggested that women experience guilt and distress when their mothering role is disrupted, and that this disruption may be had serious and long-term outcomes [8]. Disruption are found to be associated more with symptoms from illness and treatment, as some women do not experience illness as disruptive if they are asymptomatic. Disruption has also been found to be contextual, with women who have a history of disruptive life events being less perturbed by an illness diagnosis [9].

It is pertinent to note that in reviewing existing literature on the subject matter, disruption seems to be an incidental concept mentioned mainly in the titles or bodies of research articles, and not framed as a distinct concept in the literature. Focus upon mothering in the context of specific diseases is valuable, especially when trying to discern the overall effect of illness on mothering. It would be therefore valuable to examine the disruptive nature of illness in the context of mothering generally [9]. However, the concept of disrupted mothering remains unexplored or elaborated upon in the literature, and has not been previously defined [1]. No study has been done on the concept of the mothering disruption in Iran. There is therefore a need for a study that deeply explores the disrupted mothering concept and this current study intends to fill that gap using a concept analysis. A concept analysis is considered an important stage of scientific development in any discipline. In fact, concepts are the constructive blocks of theory that give rise to the development of the body of nursing knowledge [10]. Concept analysis is the term used most commonly in nursing and is generally applied to the process of inquiry that examines concepts for their level of development as revealed by their internal structure, use, representativeness, and relationship to other concepts [11]. A concept analysis makes the concept practical by providing clear and transparent definition and can serve as a basis for planning, performance and evaluation of nursing training [12]. Clarifying, recognizing, and defining concepts that describe phenomena is the purpose of concept analysis [11]. Because of the highly diverse society of Iran [13], an examination of this concept in the sociocultural context of Iranian cancer care is necessary to promote positive outcomes of mothers with $\mathrm{BC}$, contribute to healthcare providers clinical acumen when providing health services and fill gaps in professional knowledge as well as transfer this knowledge to nursing practice [9]. Defining the disrupted mothering as a phenomenon would contribute to developing strategies to support such mothers coping with cancer alongside providing motherly care for their children. Therefore, this present concept analysis was carried out with the aim of achieving an in-depth understanding of the concept of disrupted mothering in the social and cultural context of Iranian cancer care for mothers with $\mathrm{BC}$.

\section{Method \\ Design}

Several methods for development and analysis of concepts are available. One of the most widely used methods in nursing is the McEwen and Wills' Hybrid Model that refines concepts [11, 14], eliminates ambiguity in concepts and investigates them in current context and knowledge domain [15]. This method consisted of three phases in this study: theoretical, fieldwork and final integration phase [11]. The initial phase called the theoretical phase examined the literature for the concept of mothering disruption. Guidelines for Systematic Reviews and Meta-Analyses (PRISMA) was utilized (Additional file 1). At the fieldwork stage, qualitative methodology was employed to obtain data which was analyzed and consolidated criteria for reporting qualitative studies (COREQ) was made use of (Additional file 2). Finally, the integrative phase/analytical stage involved a re-examination of qualitative findings in the field in light of existing literature and an attempt was made to establish a relationship between qualitative findings in the field, findings from the literature review and clinical practice [16].

\section{The theoretical phase}

At the beginning of this phase, a search of the literature was conducted in databases including PubMed, Science Direct, Scopus, ProQuest, Google Scholar, CINAHL, Wiley, Ovid, Magiran, and SID from 2000 to 2020 with the following keywords: disrupted mothering/parenting, disrupting maternal /motherhood and breast cancer. As articles in the cancer/breast cancer setting were scanned, the search was broadened by using the main terms, 'disrupted mothering' and 'care for children'. Reference lists of identified studies were reviewed to include 
all relevant studies (hand searching). Keywords included: "Mothering disruption", "Disruption in mothering role", "Disrupting Maternal" OR "Motherhood"; Breast cancer: "Breast Neoplasm" OR "Breast Tumors" OR "Malignant Neoplasm of Breast" OR "advanced breast cancer" OR "breast cancer recurrence". Article inclusion criteria was for relevant original articles and reviews articles which included the keywords in their title or abstract and papers with full text. We excluded non-English and nonPersian Language papers and papers discussing development of instrument ( 2 articles). Overall, 1850 abstracts were reviewed and eventually 27 studies (Table 1) were entered in the analysis (Fig. 1).

The studies were screened for eligibility (selection process), and title and abstract screening were undertaken by the first author to identify publications that did not meet the inclusion criteria. The first and second authors independently screened the full texts of the selected publications to match the eligibility criteria. The following data were extracted: author name, publication year, region, sample size, study methodology and key findings as antecedents, attributes and consequences of mothering disruption. For this purpose, the selected articles were read several times and independent of each other by all authors in order to extract appropriate codes, searching for words and phrases that related to disrupted mothering. Codes were reviewed, extracted into several categories such as antecedents, attributes and consequences of mothering disruption concept [12]. The results were then reviewed by three experts in fields of women health care and concept analysis to confirm authors' perspectives on the coding and data clustering.

\section{Fieldwork phase}

A qualitative conventional content analysis approach was used to explore the experience of Iranian mothers with BC. Following ERB approval, participants were recruited using purposive sampling. The twenty participants eligible for the study were those who met the following inclusion criteria: had a confirmed diagnosis of BC, attended the oncology center of Shahid Ghazi Tabatabaei Hospital, had children 16 years and/or younger who were living with the participant and had deep and rich experiences about mothering during $\mathrm{BC}$ and its treatment. Participants were mostly aged 35-49 years, had completed a course of initial treatment for BC in the last one year and were also at the follow-up stage without any signs of recurrence. Methods to ensure the protection of human rights, including the voluntary nature of participation were discussed with participants and oral and written informed consent was obtained from them at the beginning of the interview. Data were collected by the primary researcher. Participants were interviewed at a place of their choice, with each interview audiotaped and lasting 35-80 min. The interview continued until data saturation.

The interview guide developed for this study is provided as Additional file 3. The example of questions asked the participants included "Based on your own experience of motherhood, what comes to your mind, when you hear about the disrupted mothering in childcare?", "What happens in the care of your children that makes you feel your role as a mother is impaired?", and "If your role as a mother was to be impaired, what do you think would be the outcome, for you and other family members?" The transcripts were analyzed with conventional content analysis following guidelines by Graneheim and Lundman [39] and analysis process included open coding, creating categories, and abstraction. Likewise, the recorded data were transcribed and attributes and important characteristics of disrupted mothering were extracted. The MAXQDA version 10 (software) was used for data management. In order to validate the trustworthiness of the data, the interviews' transcripts and data interpretations were provided to three mothers with $\mathrm{BC}$ to compare the results with their own experiences (Member check). The peer debriefing method was also used. Thereafter, the analysis tables were discussed in weekly meetings with tutors and advisors (4 people) with sufficient skills in qualitative studies to ensure that the data analysis and interpretation is objective-orientated and are performed based on a logical and systematic approach. Codes and categories were sent to four researchers outside of research team to express their opinions concerning their credibility.

\section{Integration phase}

Finally, this analytical stage involved a comparison of findings from the field with findings that emerged during the theoretical phase (the existing literature) by the authors who sought to establish the relevance of findings to clinical practice.

\section{Results}

\section{Theoretical phase results}

After reviewing the literature, the following definitions surfaced regarding the meaning of disrupted mothering. Disrupted mothering, has been defined as a woman perceiving that her maternal life has become disordered [1]. Letteney referred to disrupted parenting in women's caregiving capacity [40]. In the study by Grant et al., disruption referred to periods of not having custody of their children. However, disruption to mothering can take many forms and does not necessarily mean physical separation [41]. Wilson argues that with illness, a mother's ability to care for her children 


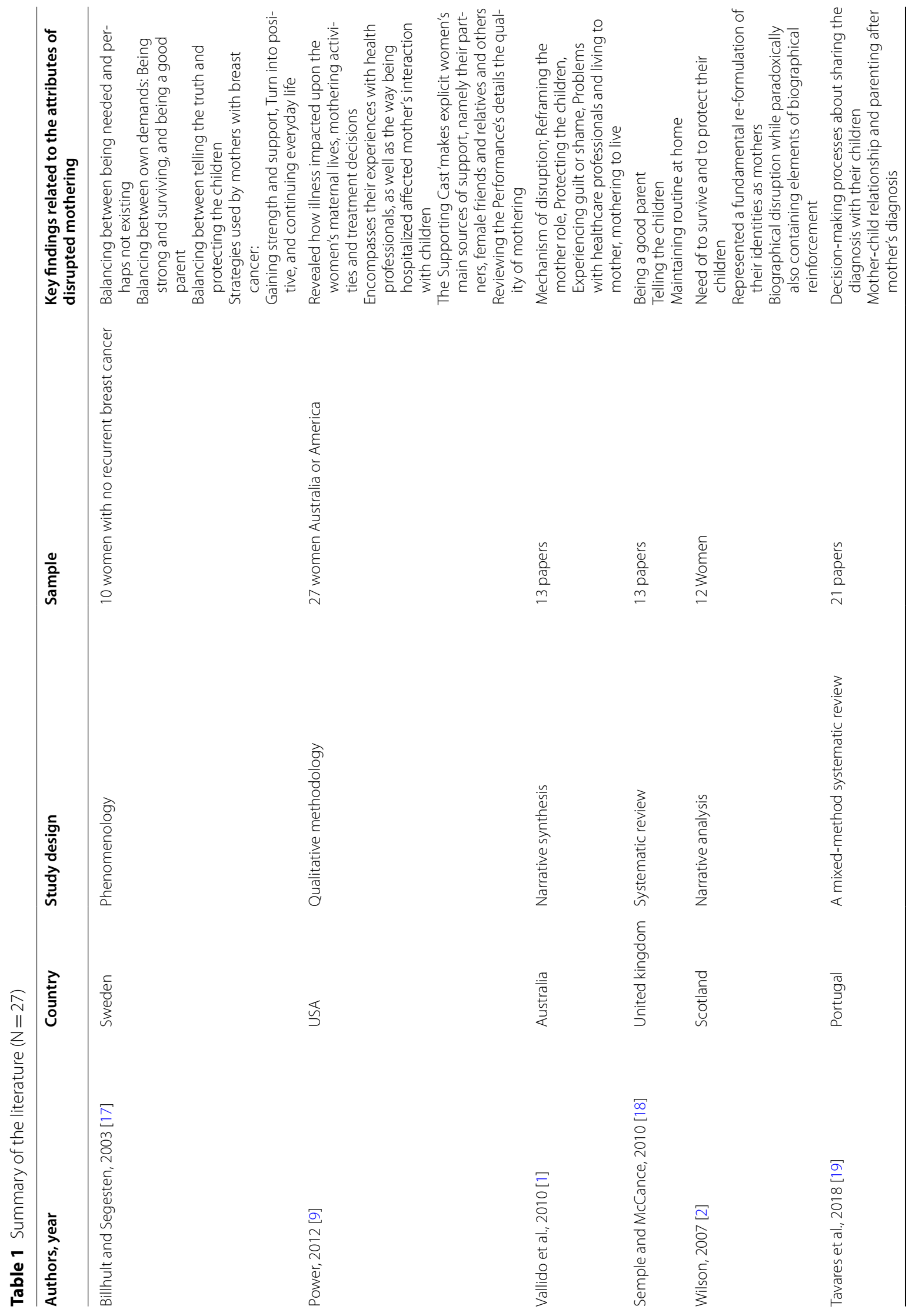


Mazaheri et al. BMC Women's Health $\quad$ (2021) 21:234

Page 5 of 17

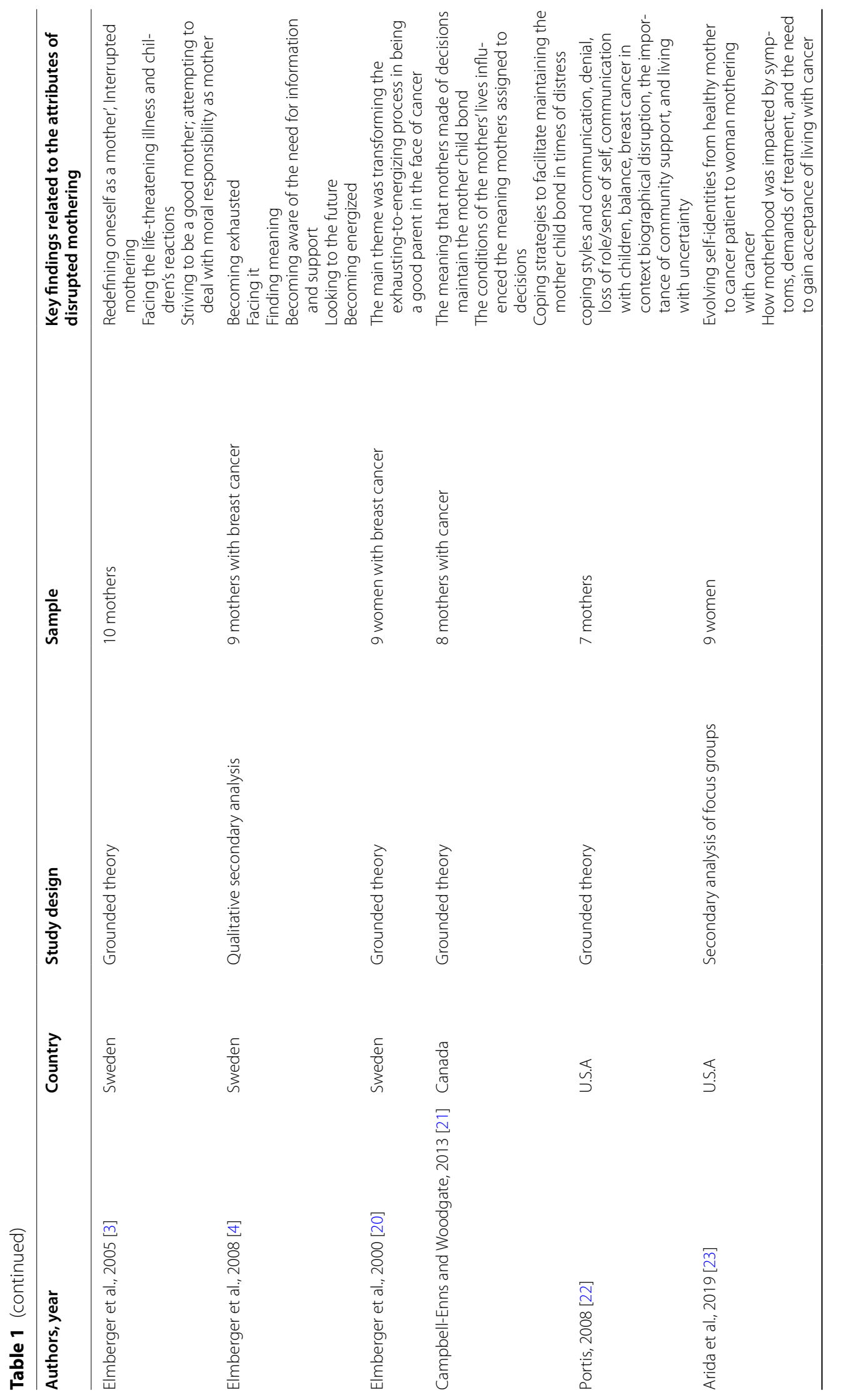




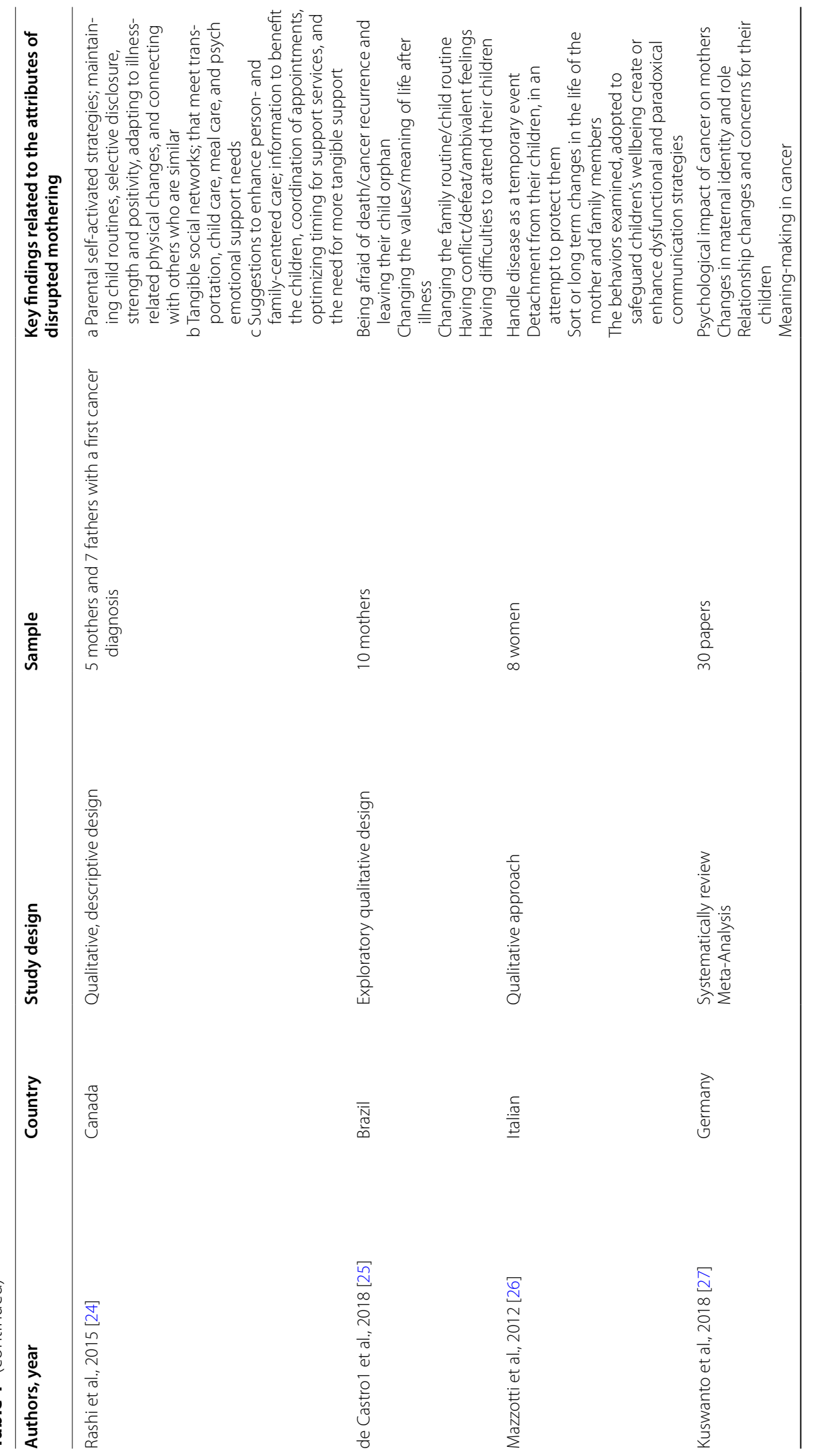




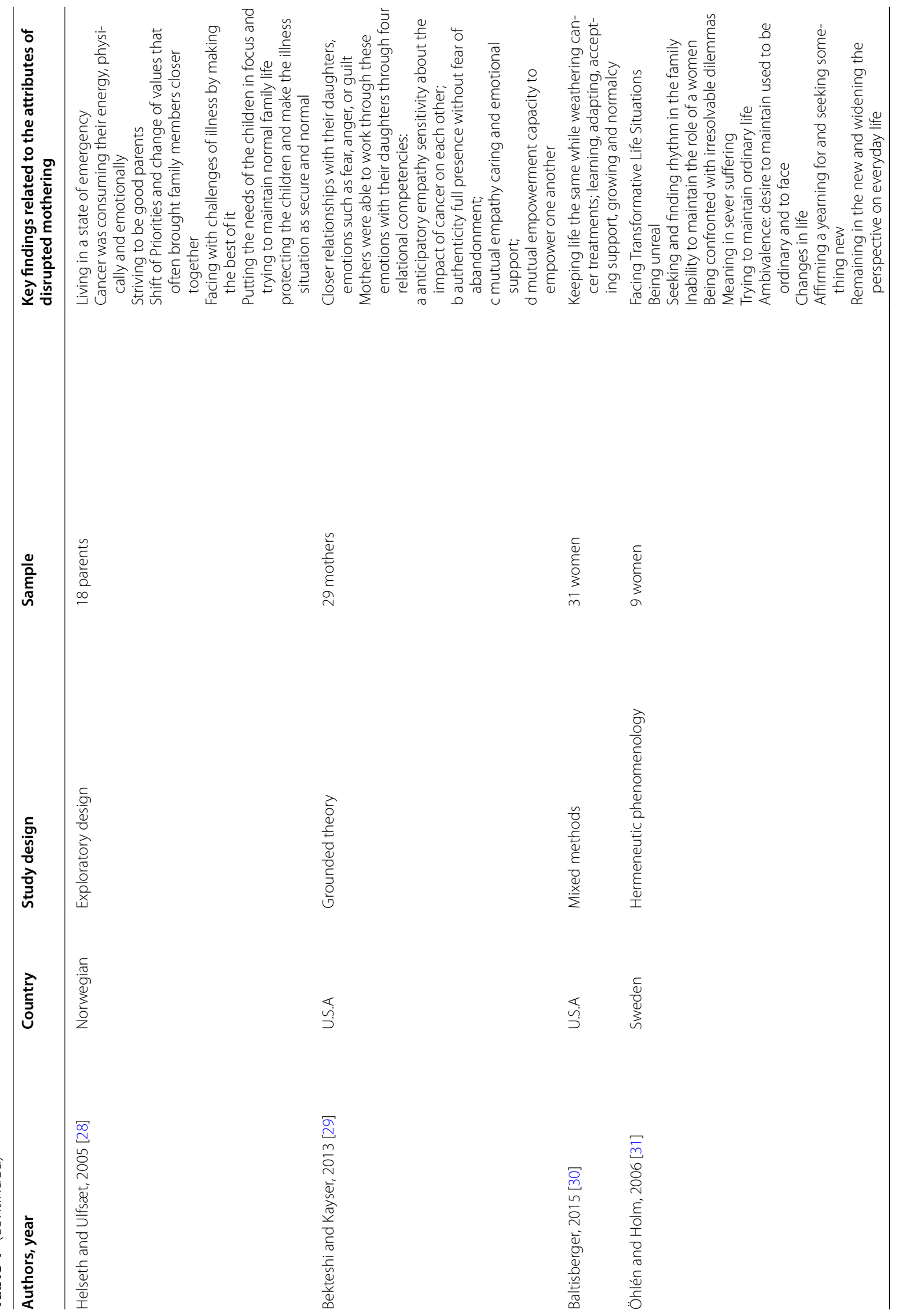




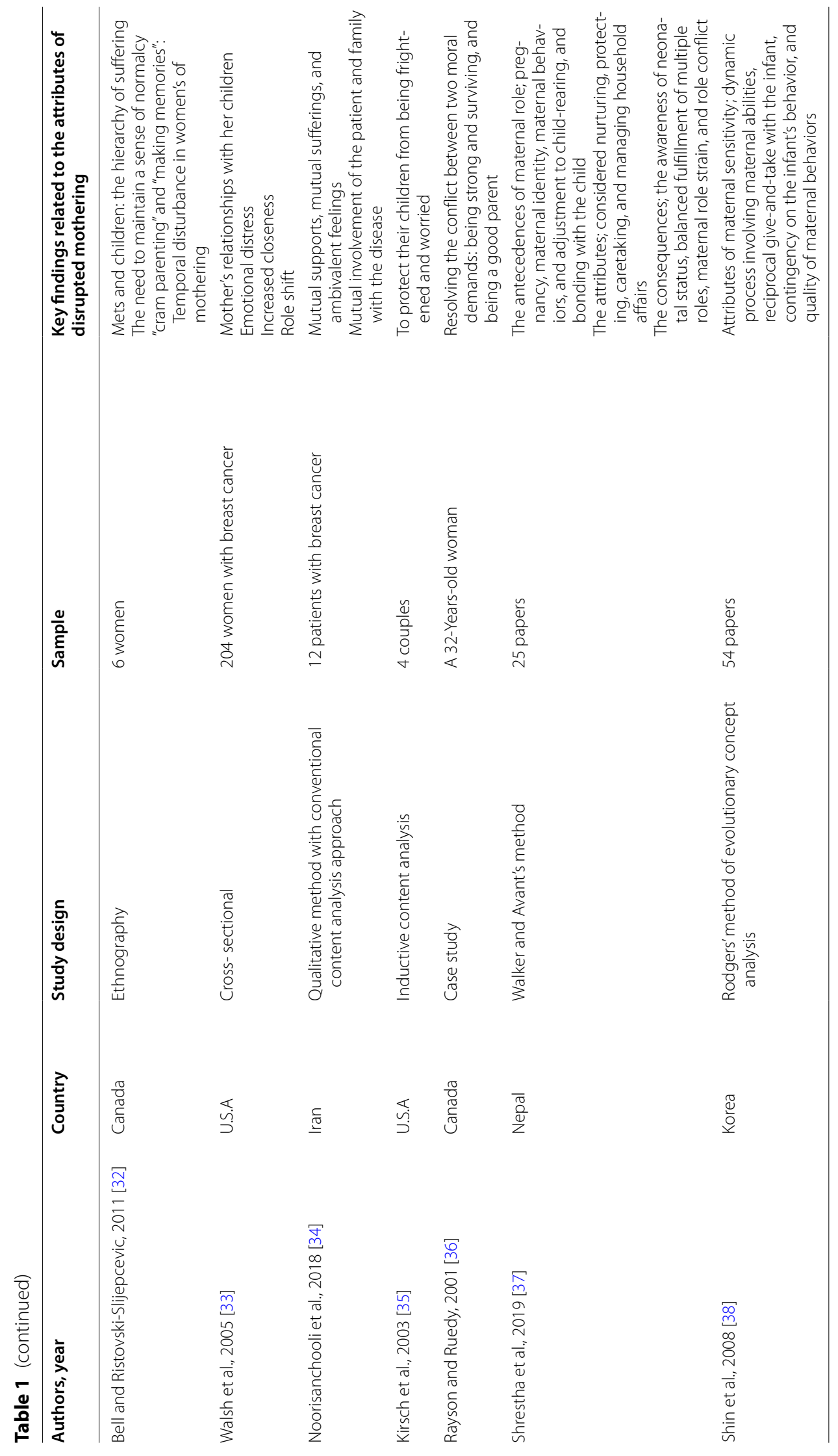




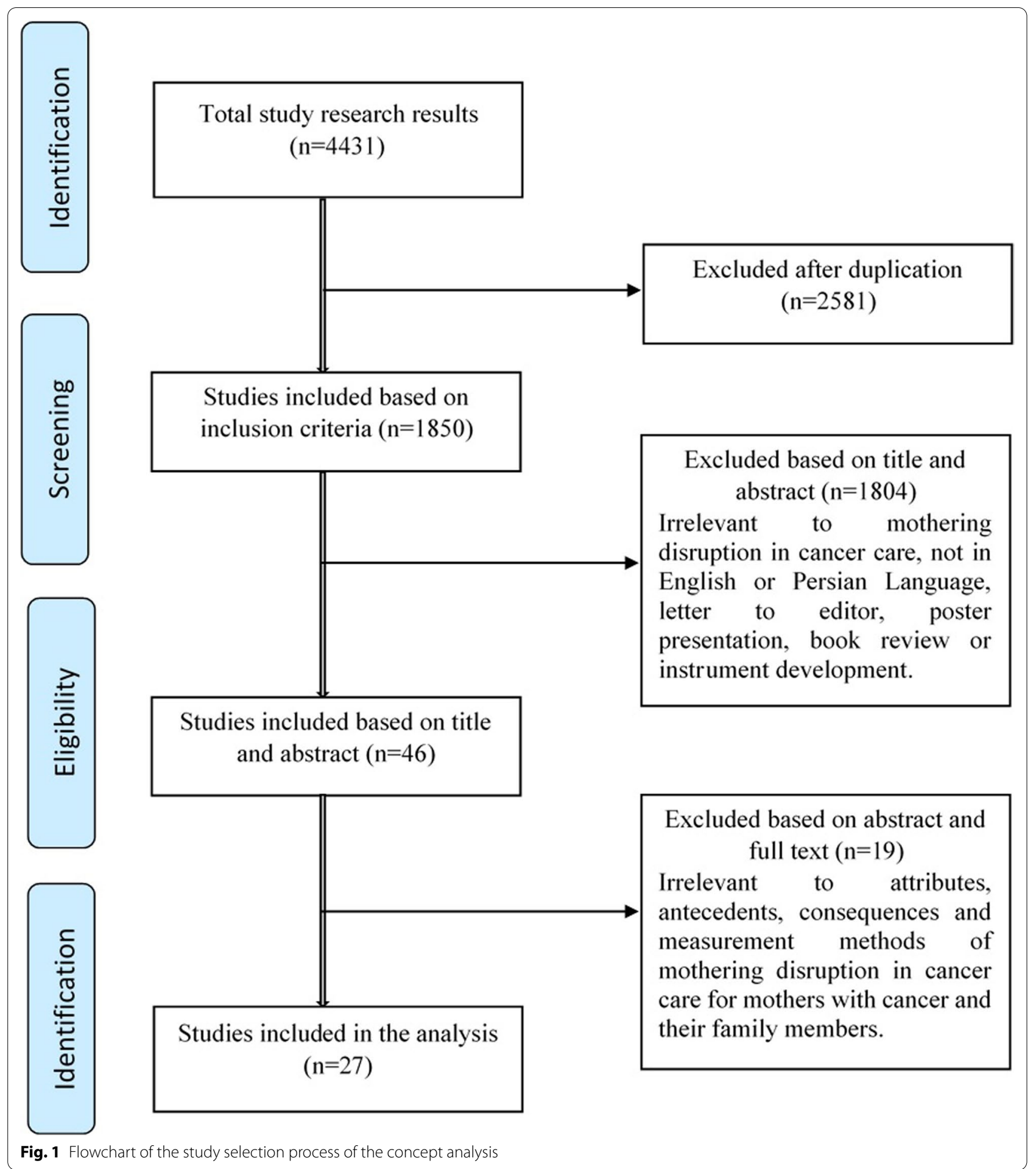

is disrupted, a situation called biographical disruption [2]. Becker defined disruption as a part of the human condition. Disruption is therefore viewed as chaotic as it makes it difficult to fulfil cultural ideals and ideologies. Furthermore, the inability to fulfil these ideals threatens a person's ability to see themselves as a moral being [42].

In the Table 1, the studies reviewed are listed along with the author's name, publication year, region, sample and its size, methodology of the study, and Key findings 
related to the attributes of disrupted mothering. The following attributes of disrupted mothering were gleaned from the literature search:

\section{Disturbance in maternal identity and roles}

These include evolving self-identities from healthy mother to patient (23), and loss of role/sense of self and self-preservation (24). Mercer viewed maternal identity as the end point of the process of role attainment and articulated the stages of role attainment (anticipatory, formal, informal, and personal) during which maternal role behaviors evolve [43]. In the personal stage, the mother acquires confidence and competence in the performance of her role, thus establish the maternal identity [44]. However, because the continuous evolution of the mother's personality in the face of life challenges in child-rearing which may erode mother's self-confidence in her ability to rear her children (hence the 'disruptive mothering'), Mercer proposed that the term, 'Becoming a mother' more aptly defines the constant change in the maternal identity [43].

The literature search revealed various concepts of the maternal role. Maternal role was defined as the behavioral responses to the expectations from a new mother and the mother's perception of responsive mothering [45]. In another, maternal role was defined as a process that help the mother achieve competence and integrate the mothering behaviors into an established role in a way that makes her feel comfortable with her identity as a mother. The search also revealed that maternal role has two components, child care, and cognitive-affective activities, the latter which includes motherliness and attitudes of tenderness, awareness, and concern for the child's needs and desires $[43,46]$. Also, the defining attributes of the maternal role were considered to include nurturing, protecting, caretaking, and managing household affairs [37].

\section{Maternal insensitivity and unresponsiveness}

Maternal responsiveness is defined as promptness or frequency of response to the infant's signals [47]. However, responsiveness to infant's cues can be considered as one aspect of maternal sensitivity and maternal responsiveness has been used interchangeably with maternal sensitivity [48]. Maternal sensitivity has been identified as a dynamic process involving a mother's responses following perception and interpretation of her infant's cues. The literature search revealed that there may be some subtle differences between maternal responsiveness and sensitivity. Maternal responsiveness has been described as responding to infants' physical and emotional needs, while maternal sensitivity includes maternal behaviors that show sensitivity even to infants' mental states [49]. It is stated that the most important factor distinguishing maternal responsiveness from maternal sensitivity is the absence of any qualitative aspect of the mother's behavior and only promptness or frequency of the mother's responses contribute to responsiveness; whether those behaviors are appropriate or not is not considered a focus of maternal responsiveness [47]. On the other hand, maternal sensitivity takes into account the quality or appropriateness of maternal responsiveness to the infant [50]. Thus, findings of this literature review would attest to the fact that disruption of the mothering role is akin to a lack of maternal responsiveness and maternal sensitivity as it can be equated to failure to respond to the behaviors of children and disruption in the process of child care".

\section{The career disruption process}

Mothers with $\mathrm{BC}$ are distressed by the times, when their illness, through hospitalization and treatment, fatigue or disability, prevents them from caring for their children as they normally would. The prognosis, treatment and nature of the diseases means that the disruption is experienced in different ways, from having less energy for caring for and playing with children, to physical separation and increasing disability, future hospitalization or impending death. Mothering could be disrupted even when women were physically present with their children [20].

\section{Biographical disruption}

Critical event is a disruptive experience in the structure of everyday life, and this experience may be labelled as a form of biographical disruption. Biographical disruptions refer to the cessation of progress in the life of an individual by reason of critical illness [51]. The concept of biographical disruptions is replete in the literature. Cancer is known to alter an individual's identity [52] and for a health crisis like $\mathrm{BC}$, biographical disruption has been described as comprising three dimensions: the body, conceptions of self, and time. It is also a concept that affects early $\mathrm{BC}$ women largely in the post-treatment period with women fearing reoccurrence and altered physical forms [53].

\section{Fieldwork phase results}

According to the analysis of the transcribed interview data, three main categories emerged for defining the mothering disruption concept. In the Table 2, the main categories are listed along with their attributes, codes and quotes. These main categories are explained below.

\section{Reduced maternal sensitivity}

Mothers with BC perceived their health status differently than healthy mothers and expressed their doubts 


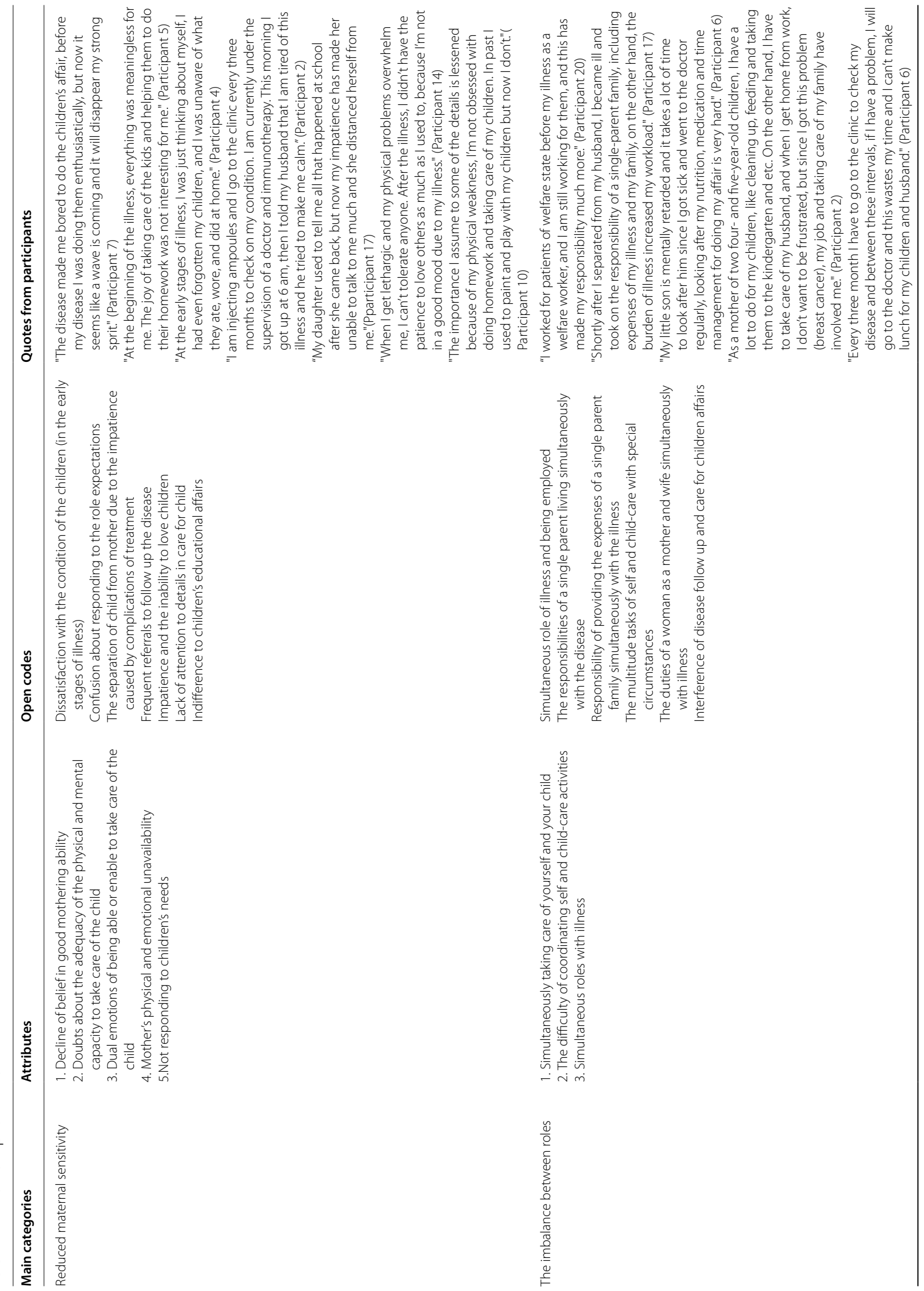




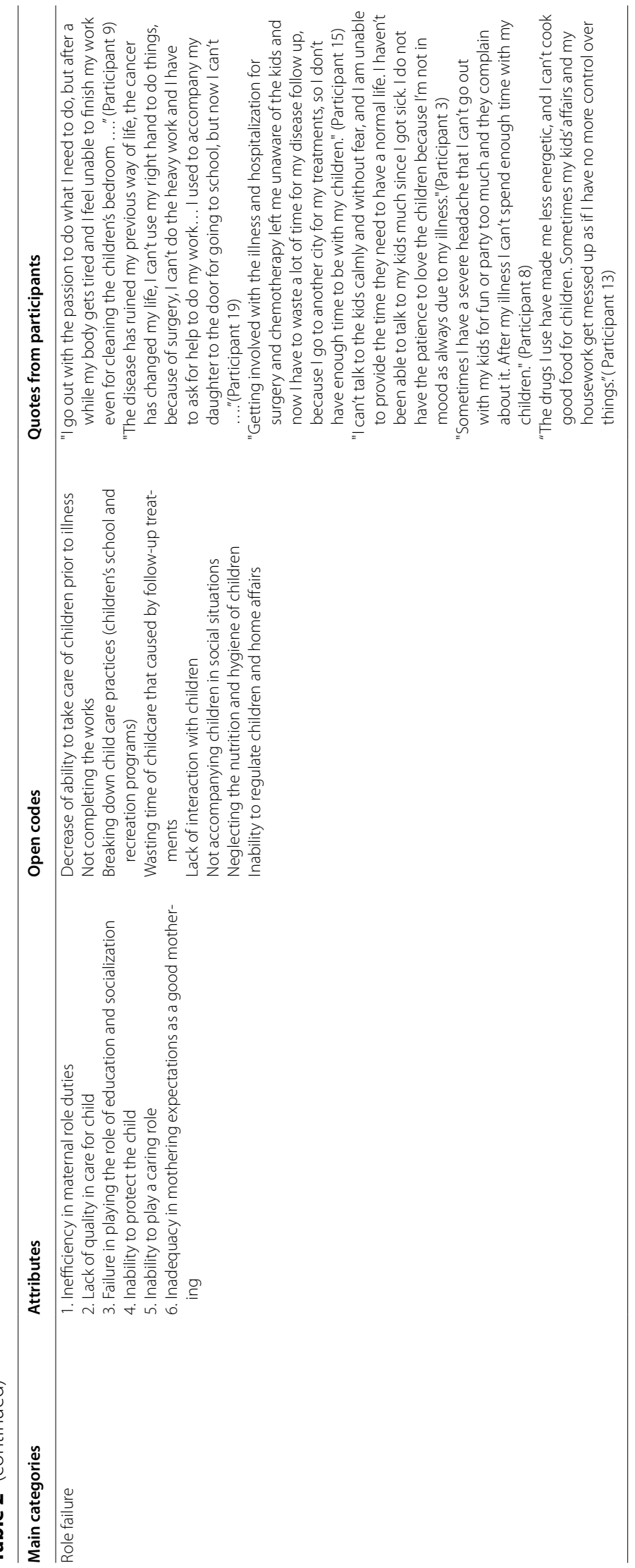


about the adequacy of care for their children due to their physical and mental (anxiety and depression) challenges, thus giving rise to a decline in the belief in good mothering ability. The authors perceive this to be a form of reduced maternal sensitivity. Reduced maternal sensitivity or maternal insensitivity is the inability of mothers to respond to behaviors arising from children's needs. Mothers reported that they sometimes felt incapable of caring their children as any ideal mother would, and the conflicting feelings of being able or unable to care for children made them physically and mentally exhausted the more. They also reported that in a bid to pursue rigorous and aggressive treatment regimens and to overcome fatigue of $\mathrm{BC}$ by having long rests, they became physically and emotionally detached from their relationship with their children and thus were unavailable to respond to their children's needs.

\section{The imbalance between roles}

Another concept that emerged from the interviews was an imbalance between roles as typified by the mothers' accounts of juggling the role of self-care with child care. The mothers reported that in the course of the illness, they had disease-related needs that had to be met in order for them to be able to continue their maternal role and for their health to be restored to a reasonable quality. Many reported being faced with issues like fatigue, disability, and motor limitations, added to the need to complete their treatment regimen. This often clashed with the expectations of the society in which they found themselves. Some mothers in this study admitted to trying to prioritize their children's needs with regards to maternal duties, but physical disabilities and symptoms of the disease often made it difficult for them to coordinate self-care and child-care activities. Others complained of being emotionally impaired from being employed and having multiple roles at the same time, such as attending to spousal need, motherhood and illness, thus making the role of mother tedious and less attractive.

\section{Role failure}

In discussing maternal role failure, inefficiency in executing maternal roles was cited by many as a cause of role failure by some mothers. Many of the mothers reported being burdened by numerous duties which included education and protection of children in a background of illness and unpleasant treatment complications, the latter often making it difficult for such mothers to have regular access to their children. Thus, a reduction in the mothers' interactions with their children led to poor quality of care for child. Consequently, mothers were seen by family members and neighbors alike as having failed to meet expectations of maternal role, in terms of education, socialization, and protection as a good model of motherhood (responsibility, responsiveness and attention to physical and psychological needs of children).

\section{Integration phase results: integrated definition of mothering disruption concept}

After analyzing all aspects of the concept using a hybrid model and based on all the two phases discussed above, The authors classified the findings of the previous two stages into three categories to explain the integrated definition of mothering disruption, which included (1) disease as threating maternal role and identity, (2) inability to interpret and respond to child behavior, and (3) support for transitioning from being patient toward maternal competency.

Authors arrived at the following conclusions about the opinions of this cohort of Iranian mothers with $\mathrm{BC}$ regarding disrupted mothering. In their opinion, the overbearing and difficult situation they faced arising from the illness and its treatment combined with the continuation of the mothering role threatened their maternal role and identity. Also grossly affected was their ability to interpret and respond to their children's behaviors and needs, especially the dependent ones, even when they tried to ignore the burden of the illness and 'being a patient' and just carry out their mothering role. Thus, mothers need the help of people around them for support as they transition from being sick to recovering and being able to playing theirs roles as mothers (Table 3).

\section{Discussion}

Mothers with $\mathrm{BC}$ struggle with physical, mental, and social challenges after diagnosis and cancer treatment and this negatively impacts on their family life as many are unable to fulfil their mothering role subsequently [54] as they are caught in-between two conflicting roles or identities: the pre-diagnosis identity of mother and the post-diagnosis identity of 'patient' [55]. While some research has been conducted on the experiences of mothers with various illnesses in general and cancer in particular, and how these impact on their roles as wives, mothers and homemakers $[1,32,56]$, very little is known about this from the perspective of women living in Iran with BC. The traditional Iranian society is patriarchal [57], characterized by a strict division of labor between men and their wives where the daily administration of household issues, care of children and training of female offspring for their future domestic roles is the exclusive preserve of the mother and the father plays an authoritative-directive control role [58]. Thus, this findings from study are pertinent as they revealed the relationship between mothering and cancer disruption, a situation termed 'disrupted mothering', among Iranian women and 
Table 3 Theoretical, fieldwork, and integration phases results

\begin{tabular}{|c|c|c|c|}
\hline \multirow[t]{2}{*}{ Theoretical phase } & \multirow[t]{2}{*}{ Fieldwork phase } & \multicolumn{2}{|l|}{ Integration phase } \\
\hline & & Category & Subcategory \\
\hline $\begin{array}{l}\text { Disturbance in maternal identity and } \\
\text { roles }\end{array}$ & Reduced maternal sensitivity & $\begin{array}{l}\text { Disease as threating maternal role } \\
\text { and identity }\end{array}$ & $\begin{array}{l}\text { 1. Unbalancing in roles as identity } \\
\text { threat of mothering } \\
\text { 2. Waiver of duties other roles to } \\
\text { achieve balance in mothering role } \\
\text { 3. Disease as imposing an unwanted } \\
\text { role }\end{array}$ \\
\hline $\begin{array}{l}\text { Maternal insensitivity and unrespon- } \\
\text { siveness }\end{array}$ & The imbalance between roles & $\begin{array}{l}\text { Inability to interpret and respond to } \\
\text { child behavior }\end{array}$ & $\begin{array}{l}\text { 1. Apparently little communication but } \\
\text { actually fighting for each other } \\
\text { 2. Physical and emotional disrupted } \\
\text { 3. Disease as consuming mother's } \\
\text { energy } \\
\text { 4. Tired of taking care yourself and } \\
\text { children } \\
\text { 5. Mothering under negative emotions } \\
\text { from fear to shame }\end{array}$ \\
\hline The career disruption process & Role Failure & $\begin{array}{l}\text { Support for transitioning from being } \\
\text { patient toward maternal compe- } \\
\text { tency }\end{array}$ & $\begin{array}{l}\text { 1. Dependence on role playing } \\
\text { 2. Disruption as an opportunity to } \\
\text { restore role } \\
\text { 3. Decreased capacity role playing } \\
\text { 4. Need to support to mother's role } \\
\text { playing } \\
\text { 5. The Supporting cast: maintenance of } \\
\text { maternal responsibility by supporting } \\
\text { their children }\end{array}$ \\
\hline
\end{tabular}

will provide culturally-sensitive approach by clinicians to the care of these women. In this study, three constructs were identified: cancer disease threating maternal role and identity, inability to interpret and respond to child behaviors and needs, and support for transitioning from being a patient to maternal competency.

One aspect of the life of the woman with $\mathrm{BC}$, which is her self-identity, is often under assault as a result of the disease and its treatment. Strickland has suggested following the cancer diagnosis, the mother finds herself unintentionally in a very difficult situation where she tries hard to be both a good patient and a dedicated mother [59]. The threat to maternal role and identity expressed by mothers in this study echoes the findings of Fisher and Connor where mothers felt confused, isolated, more like 'objects' and no longer like mothers once cancer treatment was commenced [54]. The loss of the mothering identity is further aggravated by having dependent children [60,61]. Besides maternal competence, mental health of the mothers is often affected [28]. Majority of participants stated that the being a cancer patient was an unwanted role which led to the need for simultaneous self and child-care, and that the difficulty of coordinating and balancing these needs led to an imbalance between the roles. Also, mothers reported being forced to give up some of their duties in a bid to balance their maternal role, sometimes to the detriment of the children, a concern that is equally mirrored among Korean women with BC [62]. The opinions expressed by the Iranian mothers in this study also validates the assertions put forward by Bertero and Wilmoth following a meta-synthesis of qualitative research, that breast cancer affects the identity of women with $\mathrm{BC}$ irrespective of race or ethnicity [63]. Therefore, clinicians, especially nurses, should be aware of the conflicts that may arise in the identity of the woman with cancer so as to fashion suitable programs that will help such patients and support them as they transition between the role of mother and that of patient.

The second construct in this concept analysis was "the inability of mothers to interpret and respond to their children's behaviors and needs. The cancer diagnosis is known to affect patients' psychology as well as their confidence in carrying out their parenting role [19]. It has been observed that at all phases of the cancer journey, mothers are constantly worrying about their children's well-being and some even go to great lengths to keep the knowledge of the disease from their children [59, 64]. The narratives obtained when analyzing the issues that gave rise to this second construct attest to that observation as participants reported that being involved in illness and treatment had reduced the physical and mental energy they had previously to engage in simultaneous care of themselves and of their children. They also reported that 
reduced communication with children due to fatigue led to physical and emotional disruption in such a way that they were unable to understand their children's behaviors because they spent insufficient time with them and thus were unable to respond appropriately to their behaviors and needs. A cohort of Canadian mothers with cancer whose opinions were sought on this issue, divulged strategies to overcome their inability to respond to their children's needs. Some of these strategies included making frequent phone calls, using Skype ${ }^{\mathrm{TM}}$ to talk with the children during periods of hospitalization, paying more attention to the children's verbal and non-verbal communication cues to watch out for behavioral changes [64].

Many of the women felt they were not recognized as mothers, but instead were treated as 'just a patient' and had a lot of troubles fulfilling their responsibilities regarding the well-being of children and the stability of family life. This is the bane of the third construct of analysis which was "support for transitioning from being patient toward maternal competency." This narrative affirms previous findings that point to the need for a strong support structure for women with $\mathrm{BC}$ during the entire disease and treatment continuum and beyond and nurses can address their concerns. Previous evidence suggests that the usual services provided in health centers do not fit the needs of mothers, as the diagnosis of cancer can be very destructive and complex, given the unique position of women in playing their role as mothers [59]. This is even more pertinent for women in the Iranian society who are burdened with the responsibility to organize the affairs of their homes. In this regard, they need the support of nurses in clinical and social settings [6]. Nurses can get acquainted with the attributions of the concept of mothering disruption, and help mothers in their transition from a sick mother to a healthy mother and performing their mothering duties. One way the authors posit this can be achieved is by exploring the women's coping strategies by nurses. This may help the women make the transition between mother and patient back and forth, seamlessly. The previous studies have identified several largely positive coping strategies used by Iranian Muslim women with breast cancer which include acceptance of the disease as the will of God, intentional forgetfulness, active and passive acceptance, interaction with other patients with BC and spousal support or support from significant others. Such patients need to be encouraged by their healthcare providers to move to the point in their lives where they can live near-normal lives despite their predicament $[65,66]$.

Although this study possesses many strengths, it is not without limitation. This study was limited to patients who received follow-up at a single hospital.
Therefore, their experiences might not be generalizable to the general population of Iranian mothers with BC. However, the authors consider that it will be relevant locally in Tabriz and similar regions of Iran.

\section{Conclusions}

In sum, this study is significant in that it is the first time a study has proposed a conceptual definition of the mothering disruption of these mothers in Iran. It reveals that Iranian women with $\mathrm{BC}$ express the same fears and concerns regarding the disruption of their mothering roles and identities, as other mothers with BC globally. The definitions, attributes, antecedents, consequences, and integrated definition of mothering disruption identified in the present study can be used to evaluate mothering disruption in healthcare settings and develop theory-based interventions for decreasing this disruption in mothers with BC. This concept analysis provides information, which can be used in nursing practice, education, research, and management.

By analyzing the concept of disrupted mothering as conducted in this study, through the integration of narratives provided by the women with $\mathrm{BC}$ with the evidence from scientific literature, an opportunity has been created for healthcare providers in caring for Iranian women with $\mathrm{BC}$ to have a better understanding of the experiences of their patients in order to tailor the care and support these women receive to enable them retain their mothering identities, fulfil their mothering roles and still judiciously comply with all treatment decisions raised during their care in hospital and in the post-hospitalization period. While this study has attempted to fill the gaps in literature concerning disrupted mothering in the context of women in an Islamic culture, it also facilitates clinical and transferable knowledge in nursing performance and it can help nurses and other clinicians choose the appropriate interventions to help these mothers find a balance between self-care and other mothering roles.

Future research directions would include specific culturally-sensitive psychosocial interventions targeted at eliminating the disruptions in mothering and the development of tools to measure the level of disruption in mothering, by the healthcare providers to aid in early identification and prompt resolution of disruptions in the mothering role and identity. In addition, as the definition of disrupted mothering is likely to vary across treatment stages, further comparative research is needed to analyze the concept of mothering disruption in the early and late stages of breast cancer disease and treatment continuum. 


\section{Abbreviation}

$\mathrm{BC}$ : Breast cancer.

\section{Supplementary Information}

The online version contains supplementary material available at https://doi. org/10.1186/s12905-021-01346-w.

Additional file 1. The PRISMA Checklist for study.

Additional file 2. The COREQ Checklist for study.

Additional file 3. The interview guide was developed for the study.

\section{Acknowledgements}

We gratefully acknowledge all mothers who participated in his study.

\section{Authors' contributions}

EM, AG, LV and VZ contributed to the study design. EM, AG and TCO carried out the review of literature and synthesis of the theoretical phase. All authors contribute in the data analysis and integration phase. EM collected data and drafted the manuscript. AG, TCO, LV and VZ provided critical reversion. All authors read and approved the final manuscript.

\section{Funding}

This study was financially supported by Tabriz University of Medical Sciences, Tabriz, Iran (Grant Numbers: 1396.1253).

\section{Availability of data and materials}

The datasets used and/or analyzed during the current study are available from the corresponding author on reasonable request.

\section{Declarations}

\section{Ethics approval and consent to participate}

Ethical approval of this study was obtained from the Ethical Review Board of Tabriz University of Medical Sciences, Tabriz, Iran (Code no. TBZMED.1396.1253). Study participation was voluntary, and all participants signed a written informed consent.

\section{Consent for publication}

Not applicable.

\section{Competing interests}

No conflicts of interest have been declared by the authors.

\begin{abstract}
Author details
'Students' Research Committee, Tabriz University of Medical Sciences, Tabriz, Iran. ${ }^{2}$ Department of Medical Surgical Nursing, School of Nursing and Midwifery, Hematology and Oncology Research Center, Tabriz University of Medical Sciences, Shariati Jonubi Avenue, PO Box 5138947977, Tabriz, Iran. ${ }^{3}$ Department of Pediatric Nursing, School of Nursing and Midwifery, Tabriz University of Medical Sciences, Tabriz, Iran. ${ }^{4}$ Department of Medical Surgical Nursing, School of Nursing and Midwifery, Tabriz University of Medical Sciences, Tabriz, Iran. ${ }^{5}$ Pain Physician, Palliative Medicine Physician, Department of Anaesthesia/Pain and Palliative Care Unit, Multidisciplinary Oncology Centre, College of Medicine, University of Nigeria, Ituku-Ozalla Campus, Enugu, Enugu State, Nigeria.
\end{abstract}

Received: 13 July 2020 Accepted: 6 May 2021

Published online: 05 June 2021

\section{References}

1. Vallido T, Wilkes L, Carter B, Jackson D. Mothering disrupted by illness: a narrative synthesis of qualitative research. J Adv Nurs. 2010;66(7):1435-45.
2. Wilson S. 'When you have children, you're obliged to live'1: motherhood, chronic illness and biographical disruption. Sociol Health IIIn. 2007:29(4):610-26.

3. Elmberger E, Bolund C, Lützén K. Experience of dealing with moral responsibility as a mother with cancer. Nurs Ethics. 2005;12(3):253-62.

4. Elmberger E, Bolund C, Magnusson A, Lützén K, Andershed B. Being a mother with cancer: achieving a sense of balance in the transition process. Cancer Nurs. 2008;31(1):58-66.

5. Mousvi Diva R, Moghadam N, Amani O. Evaluating family functioning and spiritual health in women with breast cancer, cancer-treated and healthy women. Iran J Psychiatr Nurs. 2017;5(5):49-56.

6. Hashemi-Ghasemabadi M, Taleghani F, Kohan S, Yousefy A. Living under a cloud of threat: the experience of Iranian female caregivers with a firstdegree relative with breast cancer. Psychooncology. 2017;26(5):625-31.

7. Akbari ME, Sayad S, Sayad S, Khayamzadeh M, Shojaee L, Shormeji Z, Amiri M. Breast cancer status in Iran: Statistical analysis of 3010 cases between 1998 and 2014. Int J Breast Cancer. 2017;2017:2481021.

8. Jackson D: Understanding women's health through Australian women's writings: A feminist exploration. Flinders University of South Australia, School of Nursing: 2000.

9. Power T: Disrupted Mothering: A drama in four acts. University of Western Sydney (Australia); 2012

10. Walker LO, Avant KC. Strategies for theory construction in nursing. Upper Saddle River: Prentice Hall; 2005

11. McEwen M, Wills EM: Theoretical basis for nursing: Lippincott Williams \& Wilkins, Philadelphia (2017).

12. Rodgers BL, Knafl KA: Concept development in nursing: Foundations, techniques, and applications: WB Saunders Co, Amsterdam (1999).

13. Aghajari P, Valizadeh L, Zamanzadeh V, Ghahramanian A, Foronda C. Cultural sensitivity in paediatric nursing care: a concept analysis using the hybrid method. Scand J Caring Sci. 2019:33(3):609-20.

14. Bousso RS, Poles K, da Cruz Dde A. Nursing concepts and theories. Rev Esc Enferm USP. 2014:48(1):144-8.

15. Rodgers BL, Knafl KA. Concept development in nursing: Foundations, techniques, and applications. New York: WB Saunders Co; 2000.

16. Schwartz-Barcott D, Kim H. Concept analysis: a hybrid model. In: Chinn $P$, editor. Nrsing research methodology: issues and implementation. Rockville: Aspen; 1986. p. 91-101.

17. Billhult A, Segesten K. Strength of motherhood: nonrecurrent breast cancer as experienced by mothers with dependent children. Scand J Caring Sci. 2003;17(2):122-8.

18. Semple CJ, McCance T. Parents' experience of cancer who have young children: a literature review. Cancer Nurs. 2010;33(2):110-8.

19. Tavares R, Brandão T, Matos PM. Mothers with breast cancer: A mixedmethod systematic review on the impact on the parent-child relationship. Psychooncology. 2018;27(2):367-75.

20. Elmberger E, Bolund C, Lützen K. Transforming the exhausting to energizing process of being a good parent in the face of cancer. Health Care Women Int. 2000;21(6):485-99.

21. Campbell-Enns HJ, Woodgate RL. Decision making for mothers with cancer: maintaining the mother-child bond. Eur J Oncol Nurs. 2013;17(3):261-8

22. Portis NC: Despair and Resilience: Mothering Through Cancer: ProQuest; 2008

23. Arida JA, Bressler T, Moran S, D'Arpino S, Carr A, Hagan TL. Mothering with advanced ovarian cancer: "you've got to find that little thing that's going to make you strong." Cancer Nurs. 2019;42(4):E54-60.

24. Rashi C, Wittman T, Tsimicalis A, Loiselle CG. Balancing illness and parental demands: coping with cancer while raising minor children. Oncol Nurs Forum. 2015:2015:337-44

25. De Castro EK, Dornel ALK, de Sousa MA (2018) The experience of motherhood during cancer treatment. In: Int J Behav Med: 2018: Springer 233 Spring ST, New York, NY 10013 USA; 2018: S78-S78.

26. Mazzotti E, Serranò F, Sebastiani C, Marchetti P. Mother-child relationship as perceived by breast cancer women. Psychology. 2012;3(12):1027.

27. Kuswanto CN, Stafford L, Sharp J, Schofield P. Psychological distress, role, and identity changes in mothers following a diagnosis of cancer: a systematic review. Psychooncology. 2018;27(12):2700-8.

28. Helseth S, Ulfsæt N. Parenting experiences during cancer. J Adv Nurs. 2005:52(1):38-46 
29. Bekteshi V, Kayser K. When a mother has cancer: pathways to relational growth for mothers and daughters coping with cancer. Psychooncology. 2013;22(10):2379-85.

30. Baltisberger JA. "Bent but not broken": a mixed methods study of mothering during chemotherapy for breast cancer. Lexington: University of Kentucky; 2015.

31. Öhlén J, Holm A-K. Transforming desolation into consolation: being a mother with life-threatening breast cancer. Health Care Women Int. 2006:27(1):18-44.

32. Bell K, Ristovski-Slijepcevic S. Metastatic cancer and mothering: being a mother in the face of a contracted future. Med Anthropol. 2011;30(6):629-49.

33. Walsh SR, Manuel JC, Avis NE. The impact of breast cancer on younger women's relationships with their partner and children. Fam Syst Health. 2005;23(1):80.

34. Noorisanchooli H, Rahnam M, Haghighi MJ, Hashemi SA, Younesbarani Z. The familial experiences of women with breast cancer referring to chemotherapy clinic: a qualitative study. Clin Cancer Invest J. 2018;7(6):210.

35. Kirsch SED, Brandt PA, Lewis FM. Making the most of the moment: when a child's mother has breast cancer. Cancer Nurs. 2003;26(1):47-54.

36. Rayson D, Ruedy S. Adjuvant chemotherapy for women with young children: our patients as parents. Commentary. J Clinl Oncol. 2001;19(1):279-81.

37. Shrestha S, Adachi K, A Petrini M, Shrestha S. Maternal role: a concept analysis. J Midwifery Reproduc Health. 2019;7(3):1730-9.

38. Shin H, Park YJ, Ryu H, Seomun GA. Maternal sensitivity: a concept analysis. J Adv Nurs. 2008:64(3):304-14.

39. Graneheim UH, Lundman B. Qualitative content analysis in nursing research: concepts, procedures and measures to achieve trustworthiness. Nurse Educ Today. 2004;24(2):105-12.

40. Letteney S. Disrupted caregiving and maternal HIV disease: a proposed model for evaluating HIV-affected children's psychosocial adjustment. Soc Work Health Care. 2010;49(8):753-63.

41. Grant T, Huggins J, Graham JC, Ernst C, Whitney N, Wilson D. Maternal substance abuse and disrupted parenting: Distinguishing mothers who keep their children from those who do not. Child Youth Serv Rev. 2011;33(11):2176-85.

42. Becker G. Disrupted lives: How people create meaning in a chaotic world Berkeley: University of California Press; 1997.

43. Mercer RT. Becoming a mother versus maternal role attainment. J Nurs Scholarsh. 2004;36(3):226-32.

44. Meighan M. Maternal role attainment-Becoming a mother. Nursing Theorists and Their Work-E-Book. 2017:432.

45. EL Barclay L, Rogan F, Schmied V, Wyllie A. Becoming a mother-an analysis of women's experience of early motherhood. J Adv Nurs. 1997;25(4):719-28.

46. Liu C, Chen Y, Yeh Y, Hsieh Y. Effects of maternal confidence and competence on maternal parenting stress in newborn care. J Adv Nurs. 2012;68(4):908-18.

47. De Wolff MS, Van ljzendoorn MH. Sensitivity and attachment: a metaanalysis on parental antecedents of infant attachment. Child Dev. 1997;68(4):571-91.

48. Bohlin G, Hagekull B, Germer M, Andersson K, Lindberg L. Avoidant and resistant reunion behaviors as predicted by maternal interactive behavior and infant temperament. Infant Behav Dev. 1989;12(1):105-17.
49. Fonagy $\mathrm{P}$, Steele M, Steele $\mathrm{H}$, Higgitt $\mathrm{A}$, Target M. The Emanuel Miller memorial lecture 1992 the theory and practice of resilience. J Child Psychol Psychiatry. 1994;35(2):231-57.

50. Meins E, Fernyhough C, Fradley E, Tuckey M. Rethinking maternal sensitivity: Mothers' comments on infants' mental processes predict security of attachment at 12 months. J Child Psychol Psychiatry. 2001;42(5):637-48.

51. Tembo AC. Critical illness as a biographical disruption. Proc Singap Health care. 2017;26(4):253-9.

52. Hubbard G, Forbat L. Cancer as biographical disruption: constructions of living with cancer. Support Care Cancer. 2012;20(9):2033-40.

53. Trusson D, Pilnick A, Roy S. A new normal?: women's experiences of biographical disruption and liminality following treatment for early stage breast cancer. Soc Sci Medicine. 2016;151:121-9.

54. Fisher $\mathrm{C}, \mathrm{O}^{\prime}$ Connor M. "Motherhood" in the context of living with breast cancer. Cancer Nurs. 2012;35(2):157-63.

55. Dorgan KA, Duvall KL, Hutson SP, Kinser AE. Mothered, mothering, and motherizing in illness narratives: what women cancer survivors in southern central appalachia reveal about mothering-disruption. J Appalachian Studies. 2013;19:59-81

56. Parton C, Katz T. Ussher JM (2019) 'Normal' and 'failing' mothers: women's constructions of maternal subjectivity while living with multiple sclerosis. Health (London). 2019;23(5):516-32

57. Moghadam VM. Patriarchy and the politics of gender in modernising societies: Iran, Pakistan and Afghanistan. Int Soc. 1992;7(1):35-53.

58. Tashakkori A, Mehryar AH. The differential roles of parents in the family, as reported by a group of Iranian adolescents. J Marriage Family. 1982;44:803-9.

59. Strickland JT. Helene Hudson Lecture Young mothers' engagement with the cancer care system. Can Oncol Nurs J. 2015;25(3):270-4.

60. Stoner JB, Stoner CR. Career disruption: The impact of transitioning from a full-time career professional to the primary caregiver of a child with autism spectrum disorder. Focus Autism Other Dev Disab. 2016;31(2):104-14.

61. Harden J. Parenting a young person with mental health problems: temporal disruption and reconstruction. Sociol Health IIIn. 2005;27(3):351-71

62. Kim S, Ko YH, Jun EY. The impact of breast cancer on mother-child relationships in Korea. Psychooncology. 2012;21(6):640-6.

63. Berterö C, Wilmoth MC. Breast cancer diagnosis and its treatment affecting the self: a meta-synthesis. Cancer Nurs. 2007;30(3):194-202.

64. Strickland JT, Wells CF, Porr C. Safeguarding the children: the cancer journey of young mothers. Oncol Nurs Forum. 2015;42:534-41.

65. Taleghani F, Yekta ZP, Nasrabadi AN. Coping with breast cancer in newly diagnosed Iranian women. J Adv Nurs. 2006;54(3):265-72.

66. Harandy TF, Ghofranipour F, Montazeri A, Anoosheh M, Bazargan M, Mohammadi E, Ahmadi F, Niknami S. Muslim breast cancer survivor spirituality: coping strategy or health seeking behavior hindrance? Health Care Women Int. 2009:31(1):88-98.

\section{Publisher's Note}

Springer Nature remains neutral with regard to jurisdictional claims in published maps and institutional affiliations.

Ready to submit your research? Choose BMC and benefit from

- fast, convenient online submission

- thorough peer review by experienced researchers in your field

- rapid publication on acceptance

- support for research data, including large and complex data types

- gold Open Access which fosters wider collaboration and increased citations

- maximum visibility for your research: over 100M website views per year

At BMC, research is always in progress.

Learn more biomedcentral.com/submissions 